\title{
Function of macrophage scavenger receptor 1 gene polymorphisms in chronic obstructive pulmonary disease with and without lung cancer in China
}

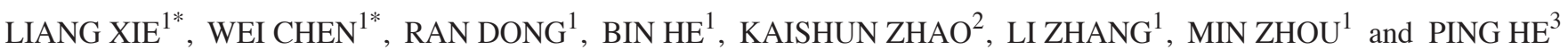 \\ ${ }^{1}$ Department of Pulmonary and Critical Care Medicine, Shanghai Institute of Respiratory Disease, \\ Ruijin Hospital Affiliated to Shanghai Jiao Tong University School of Medicine, Shanghai 200025; \\ ${ }^{2}$ Department of Respiration, Jiading Central Hospital, Shanghai 201800; ${ }^{3}$ Department of Microbiology and Parasitology, \\ Institutes of Medical Sciences, Shanghai Jiao Tong University School of Medicine, Shanghai 200025, P.R. China
}

Received June 15, 2016; Accepted August 10, 2017

DOI: $10.3892 / \mathrm{ol} .2018 .8311$

\begin{abstract}
The present study assessed the association between the variants of macrophage scavenger receptor (MSR)1 and chronic obstructive pulmonary disease (COPD), with or without lung cancer in China. COPD and lung cancer were previously regarded as two separate diseases. However, it has since been reported that there are close associations between COPD and lung cancer. Lung cancer may be an outcome of COPD. COPD may also coexist with lung cancer, and patients with COPD with lung cancer tend to have increased mortality. It is important to have a better understanding of the pathogenesis of COPD and the reason why it develops into lung cancer. MSR1 serves a crucial function in phagocytosis, which may be associated with the pathogenesis of COPD and lung cancer in patients with COPD. From 1 July 2015 to 20 February 2016, 100 patients
\end{abstract}

Correspondence to: Dr Min Zhou, Department of Pulmonary and Critical Care Medicine, Shanghai Institute of Respiratory Disease, Ruijin Hospital Affiliated to Shanghai Jiao Tong University School of Medicine, 197 Ruijin Er Road, Shanghai 200025, P.R. China E-mail: doctor_zhou_99@163.com

Dr Ping He, Department of Microbiology and Parasitology, Institutes of Medical Sciences, Shanghai Jiao Tong University School of Medicine, 280 Chongqing Southern Road, Shanghai 200025, P.R. China

E-mail: hpatsh@sjtu.edu.cn

${ }^{*}$ Contributed equally

Abbreviations: MSR, macrophage scavenger receptor; COPD, chronic obstructive pulmonary disease; SNP, single-nucleotide polymorphism; GOLD, Global Initiative for Chronic Obstructive Lung Disease; $\mathrm{FEV}_{1}$, forced expiratory volume in $1 \mathrm{sec}$; FVC, forced vital capacity; PCR, polymerase chain reaction; CAT, COPD Assessment Test

Key words: chronic obstructive pulmonary disease, lung cancer, macrophage scavenger receptor 1 , polymorphism with COPD and lung cancer, 100 patients with COPD without lung cancer and 100 healthy smokers were enrolled at the Shanghai Ruijin Hospital (Shanghai, China) for the genotyping of eight single-nucleotide polymorphisms (SNPs; ex3P36A_C>G, ex3S41Y_C >A, ex4V113A_T>C, ex4P174Y_ G>T, ex6P275A_C>G, ex6R293x_C>T, ex10G369S_G>A and ex11H441R_A $>$ G) via gene sequencing. The genotype frequencies of these SNPs did not significantly differ between patients with COPD with and without lung cancer, and the healthy controls. However, during DNA sequencing, the SNP rs13306550 (IVS4+3A>G) was identified in the splice donor site and was significantly associated with an increased risk of COPD compared with the healthy smokers $(\mathrm{P}=0.0053)$. The present study demonstrated that the variant rs13306550 was a risk factor for COPD susceptibility, but that did not influence lung cancer pathogenesis in patients with COPD. However, the mechanisms underlying the influence of rs13306550 on COPD development and progression remain to be elucidated and require further study.

\section{Introduction}

Chronic obstructive pulmonary disease (COPD) and lung cancer remain major public concerns due to the increased morbidity and mortality with which they are globally associated $(1,2)$. COPD is a risk factor for lung cancer, and studies into associations between COPD and lung cancer have suggested strategies for decreasing the burden of the conditions (3). Smoking tobacco is a leading cause of COPD (4-7). However, only a small proportion of smokers develop COPD, and only a subsection of all patients with COPD develop lung cancer (3). Therefore, host differences serve important functions in the pathogenesis of these diseases. The present study hypothesized that environmental risk factors and a genetic predisposition may facilitate the development of COPD and concurrent lung cancer. Genome-wide association studies have provided statistically significant associations between COPD and multiple gene variants that may function in its pathogenesis (8-10). Therefore, improved understanding of the genetic background of COPD and of COPD with lung cancer is crucial 
to uncovering the pathogenic mechanisms of, and developing novel therapeutic strategies for, these diseases.

Macrophages serve a key function in defending against respiratory infections. Macrophage scavenger receptors (MSRs) are located on the surface of alveolar macrophages and are associated with a range of functions, including phagocytosis, antigen presentation, apoptotic cell clearance and bacterial and particle uptake $(11,12)$. A decreased ability of alveolar macrophages to phagocytose apoptotic cells and bacteria results in inflammation, which exacerbates COPD (13). Hirayama et al (14) demonstrated that a scavenger receptor was also an independent prognostic factor in lung squamous cell carcinoma, and that it may generate tumor-promoting microenvironments. Therefore, MSR1 may serve a function in COPD and in COPD with lung cancer.

MSR1 is located on chromosome 8p22 and is composed of 11 exons (15). Bossé et al (8) provided an overview of genes associated with COPD, including MSR1. Seven missense mutations or sequence variants (ex3P36A_C $>\mathrm{G}$, ex3S41Y $\mathrm{C}>\mathrm{A}$, ex4V113A_T $>\mathrm{C}$, ex4P174Y_G $>\mathrm{T}$, ex6P275A_C $>\mathrm{G}$, ex10G369S_G>A, and ex11H441R_A $>$ G) and one nonsense mutation at codon 293 (ex6R293x_C $>$ T) have been reported to serve an important role in the structure and function of MSR1 (16). A previous study revealed that a coding single-nucleotide polymorphism (SNP; ex6P275A_C $>\mathrm{G}$ ) of MSR1 was associated with COPD susceptibility, COPD-associated measures of lung function and abnormalities (10). To the best of our knowledge, there have been no studies evaluating the association between MSR1 variants and COPD with lung cancer susceptibility. In the present study, the association between the variants of MSR1 and COPD with or without lung cancer in China was assessed.

\section{Materials and methods}

Patients. From 1 July 2015 to 20 February 2016, 100 patients with COPD with lung cancer, 100 patients with COPD without lung cancer and 100 healthy smokers were enrolled at the Department of Pulmonary \& Critical Care Medicine, Shanghai Institute of Respiratory Disease, Shanghai Ruijin Hospital Affiliated to the School of Medicine, Shanghai Jiao Tong University (Shanghai, China). The age of patients with COPD, patients with COPD with lung cancer subjects and healthy smokers was $68.33 \pm 6.47$ years, $65.79 \pm 7.77$ years and 66.47 \pm 9.67 years (data are presented as mean \pm standard deviation), respectively, and the male distribution of the three groups was 76,79 and $72 \%$, respectively. COPD was diagnosed according to the criteria proposed by the Global Initiative for Chronic Obstructive Lung Disease (GOLD) (17). Lung carcinoma was diagnosed by pathological examination by Dr. Yuan (Department of Pathology, Shanghai Ruijin Hospital Affiliated to the School of Medicine, Shanghai Jiao Tong University). Any patient with a history of bronchial asthma, diabetes, hypertension or any other associated pulmonary disease was excluded from the study. The healthy controls exhibited normal lung function without any history of COPD, cancer, asthma or any other pulmonary infectious diseases. The healthy smokers were recruited when they attended the Ruijin Hospital for medical tests from July 2015 to February 2016. The healthy controls were age-, sex- and cigarette packs smoked/year-matched for patients with COPD with and without lung cancer. In the present study, the phenotypes of COPD based on the computed tomography (CT) imaging of the chest were divided into 3 types: Emphysema, airway obstruction (airway) and mixed type (hybrid). In patients with COPD without lung cancer, $21 \%$ exhibited an emphysema phenotype, $12 \%$ exhibited airway phenotype and the rest exhibited a hybrid phenotype. In patients with COPD with lung cancer, 30\% exhibited an emphysema phenotype, $4 \%$ exhibited an airway phenotype and the rest exhibited a hybrid phenotype. All patients who participated in the present study provided written informed consent. The protocol was reviewed and approved by the Ruijin Hospital Ethics Committee of Shanghai Jiao Tong University, School of Medicine.

Lung function evaluation. Lung function tests were performed using a MasterScreen ${ }^{\mathrm{TM}}$ spirometry machine (BD Biosciences, Franklin Lakes, NJ, USA) 20 min prior to and after inhaling $400 \mu \mathrm{g}$ salbutamol (GlaxoSmithKline, Plc., Brentford, UK) Forced expiratory volume in $1 \mathrm{sec}\left(\mathrm{FEV}_{1}\right)$ and forced vital capacity (FVC) were measured. The patients were instructed to take the deepest breath they could and then exhale with maximum intensity into the spirometry machine for at least 6 sec. The bronchial dilation test was performed after the patients had inhaled $400 \mu \mathrm{g}$ salbutamol. Short-acting inhaled drugs were not administered during the $12 \mathrm{~h}$ prior to testing. Long-acting bronchodilator therapy was ceased for $24 \mathrm{~h}$ prior to testing. Theophylline sustained-release tablets and atropine were not administered for 24 and $8 \mathrm{~h}$, respectively, prior to spirometry. The present study was not a long term experiment for one subject. Blood was drawn and the lung function test was performed when patients were enrolled. The short-acting inhaled drugs, long-acting bronchodilator therapy, theophylline sustained-release tablets and atropine were not used during the study to avoid any effects of the medicine on the lung function tests. All pulmonary function tests were performed according to the GOLD criteria (18).

DNA extraction and genotyping. Genomic DNA was extracted from patient whole blood containing EDTA using a DNeasy Blood \& Tissue kit (cat. no. 69506; Qiagen, Inc., Valencia, CA, USA) according to the manufacturer's protocol, and stored at $-20^{\circ} \mathrm{C}$ until use. The genomic DNA underwent polymerase chain reaction $(\mathrm{PCR})$ in a $50 \mu \mathrm{l}$ reaction mixture (2xTaq PCR Master mix, cat. no. KT201; Tiangen Biotech Co., Ltd., Beijing, China). The template was replaced with DEPC water (Invitrogen; Thermo Fisher Scientific, Inc.) for use as the negative control. The details of the primers are summarized in Table I. The PCR reactions consisted of 35 cycles of $30 \mathrm{sec}$ at $95^{\circ} \mathrm{C}, 30 \mathrm{sec}$ at $55^{\circ} \mathrm{C}$ and $1 \mathrm{~min}$ at $72^{\circ} \mathrm{C}$. A total of 200 patients and 100 healthy controls were tested for eight SNPs (ex3P36A_C/G, ex3S41Y_C/A,ex4V113A_T/C,ex4P174Y_G/T,ex6P275A_C/G, ex6R293x_C/T, ex10G369S_G/A and ex11H441R_A/G) in the 5 exonic regions of the MSR1 gene (Table I). Due to the primer design, the size of the PCR products was increased compared with that of the exon. Therefore, variants in the adjacent intron, including rs13306550, were observed.

Statistical analysis. The distribution of age, sex and smoking pack/year of patients with COPD with or without lung cancer 
Table I. Characteristics of the SNPs of the macrophage scavenger receptor 1 gene and associated primer sequences.

\begin{tabular}{|c|c|c|c|c|}
\hline SNP & Primer sequence & Size (bp) & Region & Allele \\
\hline ex3P36A & F: 5'-CCAAAAGATCAAACAAGC-3' & 713 & Exon & $\mathrm{C} / \mathrm{G}$ \\
\hline ex3S41Y & R: 5'-GTCACCCACATTAGAAGG-3' & & & $\mathrm{C} / \mathrm{A}$ \\
\hline ex4V113A & F: 5'-AATAGGAAAGGGAGAATG-3' & 741 & Exon & $\mathrm{T} / \mathrm{C}$ \\
\hline ex4P174Y & R: 5'-TCAGGGTAAACAGGATGA-3' & & & $\mathrm{G} / \mathrm{T}$ \\
\hline ex6P275A & F: 5'-ATAGAAAAGTGTTAGGCACA-3' & 733 & Exon & $\mathrm{C} / \mathrm{G}$ \\
\hline ex6R293x & R: 5'-GATTTATTCAACGCAAAG-3' & & & $\mathrm{C} / \mathrm{T}$ \\
\hline \multirow[t]{2}{*}{ ex10G369S } & F: 5'-ATTAGTCCTTGCTTGCCTTTT-3' & 707 & Exon & G/A \\
\hline & R: 5'-ACGCTGGTCTTGAACTCATTTA-3' & & & \\
\hline \multirow[t]{2}{*}{ ex11H441R } & F: 5'-CCAAGACCCTTTGACATA-3' & & & \\
\hline & R: 5'-GACATAAAATAGTAAGCATGAA-3' & 708 & Exon & $\mathrm{A} / \mathrm{G}$ \\
\hline
\end{tabular}

SNP, single-nucleotide polymorphism; F, forward; R, reverse.

and healthy smokers all conformed to the law of normal distribution. Data were expressed as the mean \pm standard deviation. Data regarding the lung function and the COPD Assessment Test (CAT) score did not conform to the normal distribution; these were expressed as the median $\left(Q_{3}-Q_{1}\right)$. The Mann-Whitney $U$ test was used to analyze the difference in lung function tests and CAT scores between patients with COPD with and without rs13306550. An exact test was used to assess the variation in SNP rs13306550 from the Hardy-Weinberg equilibrium in all three groups $(\mathrm{P}>0.05)$. Data on the age, sex and smoking pack/year between the three groups were assessed using a one-way analysis of variance with Student-Newman-Keuls test performed as a post-hoc test. The and the variation of each SNP was assessed using Fisher's exact tests. For all tests, two-sided P-values of $<0.05$ were considered to indicate a statistically significant difference. All data were analyzed using SPSS version 22.0 (IBM Corp., Armonk, NY, USA). Each assay was performed in triplicate and independently repeated at least 3 times.

\section{Results}

Study patients. A total of 300 patients were enrolled in the present study. The characteristics of all patients are listed in Table II. Among the 100 patients with COPD, the mean age was $68.33 \pm 6.47$ and $76 \%$ were male. All patients with COPD were diagnosed according to the GOLD criteria (17). The patients with COPD smoked a mean pack/year of $45.59 \pm 32.34$. CT scanning serves a notable role in the identification of the different phenotypes of COPD. Although a majority of patients with COPD have some form of overlap between airway morphologic changes and parenchymal destruction, it is relatively easy to differentiate between those having an emphysema predominant disease and those presenting with predominant airway abnormalities. As a result, in this study, the types of COPD based on the computed tomography imaging of the chest have been divided into 3 types: Emphysema; airway obstruction (airway); and mixed type (hybrid) as reported by Grenier et al (19). The phenotype of the patients with COPD included emphysema (21\%), airway (12\%) and hybrid (67\%). Among the 100 patients with COPD with lung cancer, the mean age was $65.79 \pm 7.77$ and $79 \%$ were male. The phenotype of these patients included emphysema (30\%), airway (4\%) and hybrid (66\%). These patients smoked a mean pack/year of $44.94 \pm 20.86 ; 12 \%$ of these patients developed concurrent small cell lung cancer, $39 \%$ with squamous carcinoma and $49 \%$ with adenocarcinoma. The mean age of the healthy smokers was $66.47 \pm 9.67$ and $72 \%$ were male. The healthy smokers smoked a mean pack/year of $38.13 \pm 19.08$.

MSR1 exon variants is associated with risk of COPD with/without lung cancer. In the present study, eight SNPs (ex3P36A_C $>$ G, ex3S41Y_C $>$ A, ex4V113A_T $>C$, ex4P174Y $\mathrm{G}>\mathrm{T}$, ex6P275A_C $>$ G, ex6R293x_C $>\mathrm{T}$, ex10G369S_G>A and ex11H441R_A $>$ G) were genotyped in 300 patients, including 100 healthy smokers, 100 patients with COPD without lung cancer and 100 patients with COPD with lung cancer (Table III).

The genotype frequencies of these eight variants did not significantly differ among the three groups. It was identified that the SNP rs13306550 is significantly associated with an increased risk of COPD. However, no significant difference in the distribution of the SNP rs13306550 was demonstrated between those COPD patients with and without lung cancer $(\mathrm{P}=0.51$; Table IV). Of the patients with COPD, $10 \%$ had heterozygous mutations of rs13306550 (Fig. 1A); $13 \%$ of patients with COPD with lung cancer were positive for this variant, all of which were the heterozygous mutation (Fig. 1A). The genotyping results of patients without this polymorphism are presented in Fig. 1B.

A significant difference in the distribution of SNP rs11306550 was identified between patients with COPD with lung cancer and the healthy controls, but not the patients with COPD (Table IV). For the patients with COPD without lung cancer and the controls, and the patients with COPD with lung cancer and the controls, the odds ratio was $>1$, which suggested that the rs13306550 SNP is a harmful factor for COPD morbidity. This SNP is associated with an increased susceptibility of COPD, and smokers with rs13306550 tend to develop COPD more easily compared with those without the SNP. However, there is no evidence about this polymorphism suggesting that it may contribute to the pathogenesis of lung cancer in patients with COPD. 
Table II. Characteristics of the study patients.

\begin{tabular}{|c|c|c|c|c|}
\hline Characteristic & $\begin{array}{l}\text { Patients with COPD } \\
\qquad(\mathrm{N}=100)\end{array}$ & $\begin{array}{l}\text { Patients with COPD + } \\
\text { CA }(N=100)\end{array}$ & $\begin{array}{l}\text { Healthy controls } \\
\qquad(\mathrm{N}=100)\end{array}$ & P-value \\
\hline Age (years) & $68.33 \pm 6.47$ & $65.79 \pm 7.77$ & $66.47 \pm 9.67$ & $0.07^{\mathrm{a}}$ \\
\hline Sex (male \%) & 76 & 79 & 72 & 0.51 \\
\hline Cigarette packs smoked/year & $45.59 \pm 32.34$ & $44.94 \pm 20.86$ & $38.13 \pm 19.08$ & $0.06^{\mathrm{a}}$ \\
\hline Phenotype of COPD & & & - & - \\
\hline Emphysema & $21(21 \%)$ & $30(30 \%)$ & & \\
\hline Airway & $12(12 \%)$ & $4(4 \%)$ & & \\
\hline Hybrid & $67(67 \%)$ & $66(66 \%)$ & & \\
\hline $\mathrm{FEV}_{1} / \mathrm{FVC}(\%)$ & $49.81 \pm 11.50$ & $62.18 \pm 15.90$ & - & - \\
\hline $\mathrm{FEV}_{1} \%$ predicted & $39.82 \pm 18.00$ & $60.70 \pm 20.91$ & - & - \\
\hline Type of cancer & & & - & - \\
\hline Small cell lung cancer & & $12(12 \%)$ & & \\
\hline Squamous carcinoma & & $39(39 \%)$ & & \\
\hline Adenocarcinoma & & $49(49 \%)$ & & \\
\hline Large cell carcinoma & & 0 & & \\
\hline
\end{tabular}

${ }^{\mathrm{a}} \mathrm{P}<0.05 . \mathrm{X} \pm \mathrm{Y}$ indicates mean \pm standard deviation. Phenotype of COPD was classified according to the results of computed tomography. The type of carcinoma was defined by pathological examination. CA, lung cancer; COPD, chronic obstructive pulmonary disease; FVC, forced vital capacity; $\mathrm{FEV}_{1}$, forced expiratory volume in $1 \mathrm{sec} ; \mathrm{N}$, number of patients.

Table III. Association between macrophage scavenger receptor 1 exon variants and the risk of COPD with and without lung cancer.

\begin{tabular}{lcccc}
\hline SNP & Genotype & $\begin{array}{c}\text { Patients with COPD } \\
(\mathrm{N}=100)\end{array}$ & $\begin{array}{c}\text { Patients with COPD + CA } \\
(\mathrm{N}=100)\end{array}$ & $\begin{array}{c}\text { Healthy controls } \\
(\mathrm{N}=100)\end{array}$ \\
\hline ex3P36A & CC & 100 & 100 & 100 \\
ex3S41Y & CC & 100 & 100 & 100 \\
ex4V113A & TT & 100 & 100 & 100 \\
ex4P174Y & GG & 100 & 100 & 100 \\
rs13306550 & AA & 90 & 87 & 99 \\
& GG & 10 & 13 & 1 \\
ex6P275A & GG & 0 & 0 & 0 \\
& CC & 98 & 100 & 99 \\
ex6R293x & GG & 2 & 0 & 0 \\
ex10G369S & GC & 0 & 100 & 100 \\
ex11H441R & GG & 100 & 100 & 100 \\
\hline
\end{tabular}

Data are adjusted for sex, age and smoking. CA, lung cancer; COPD, chronic obstructive pulmonary disease; SNP, single-nucleotide polymorphism.

Rs13306550 SNP is not significantly associated with COPD severity. To assess whether SNP rs13306550 serves a crucial function in COPD severity, the results of lung function tests and the CAT score were analyzed between the patients with COPD with and without this SNP. Data regarding lung function and the CAT score did not conform to the normal distribution and thus were expressed as the median $\left(\mathrm{Q}_{3}-\mathrm{Q}_{1}\right)$. The Mann-Whitney $\mathrm{U}$ test was used to analyze the data. The results indicated no significant difference in lung function between patients with
COPD with and without the SNP rs13306550 (Table V). The results of $\mathrm{FEV}_{1} / \mathrm{FVC}, \mathrm{FEV}_{1} \%$ predicted and the CAT scores between the patients and the controls did not significantly differ.

\section{Discussion}

To evaluate the association between MSR1 variants and the risk of COPD with and without lung cancer, seven missense mutations (Pro36Ala, Ser41Tyr, Val113Ala, Asp174Tyr, 
Table IV. Association of the macrophage scavenger receptor 1 gene polymorphism rs13306550 with the risk of COPD and coexistence of COPD and lung cancer.

A,

\begin{tabular}{|c|c|c|c|c|c|c|c|}
\hline \multirow[b]{2}{*}{ Genotype } & \multicolumn{2}{|c|}{$\begin{array}{l}\text { Patients with } \\
\text { COPD }(\mathrm{N}=100)\end{array}$} & \multicolumn{2}{|c|}{$\begin{array}{l}\text { Healthy controls } \\
\qquad(\mathrm{N}=100)\end{array}$} & \multirow[b]{2}{*}{ Crude OR (95\% CI) } & \multirow[b]{2}{*}{ Adjusted OR (95\% CI) } & \multirow[b]{2}{*}{ P-value } \\
\hline & $\mathrm{N}$ & $\%$ & $\mathrm{~N}$ & $\%$ & & & \\
\hline $\mathrm{AA}$ & 90 & 90 & 99 & 99 & 1.00 & 1.00 & \\
\hline AG & 10 & 10 & 1 & 1 & $11.00(1.38-87.64)$ & $12.07(1.51-95.52)$ & 0.0053 \\
\hline GG & 0 & 0 & 0 & 0 & & & \\
\hline
\end{tabular}

$\mathrm{B}$,

\begin{tabular}{|c|c|c|c|c|c|c|c|}
\hline \multirow[b]{2}{*}{ Genotype } & \multicolumn{2}{|c|}{$\begin{array}{c}\text { Patients with } \\
\text { COPD+ }(\mathrm{N}=100)\end{array}$} & \multicolumn{2}{|c|}{$\begin{array}{l}\text { Healthy controls } \\
\qquad(\mathrm{N}=100)\end{array}$} & \multirow[b]{2}{*}{ Crude OR (95\% CI) } & \multirow[b]{2}{*}{ Adjusted OR (95\% CI) } & \multirow[b]{2}{*}{ P-value } \\
\hline & $\mathrm{N}$ & $\%$ & $\mathrm{~N}$ & $\%$ & & & \\
\hline AA & 87 & 87 & 99 & 99 & 1.00 & 1.00 & \\
\hline $\mathrm{AG}$ & 13 & 13 & 1 & 1 & $14.79(1.90-115.4)$ & $15.30(1.92-121.76)$ & 0.00088 \\
\hline GG & 0 & 0 & 0 & 0 & & & \\
\hline
\end{tabular}

$\mathrm{C}$,

\begin{tabular}{|c|c|c|c|c|c|c|c|}
\hline \multirow[b]{2}{*}{ Genotype } & \multicolumn{2}{|c|}{$\begin{array}{c}\text { Patients with } \\
\text { COPD+ CA }(N=100)\end{array}$} & \multicolumn{2}{|c|}{$\begin{array}{l}\text { Patients with } \\
\text { COPD }(\mathrm{N}=100)\end{array}$} & \multirow[b]{2}{*}{ Crude OR $(95 \% \mathrm{CI})$} & \multirow[b]{2}{*}{ Adjusted OR (95\% CI) } & \multirow[b]{2}{*}{ P-value } \\
\hline & $\mathrm{N}$ & $\%$ & $\mathrm{~N}$ & $\%$ & & & \\
\hline AA & 87 & 87 & 90 & 90 & 1.00 & 1.00 & \\
\hline AG & 13 & 13 & 10 & 10 & $1.35(0.56-3.23)$ & $1.29(0.53-3.13)$ & 0.51 \\
\hline GG & 0 & 0 & 0 & 0 & & & \\
\hline
\end{tabular}

Data are adjusted for sex, age and smoking. CA, lung cancer; CI, confidence interval; COPD, chronic obstructive pulmonary disease; OR, odds ratio; $\mathrm{N}$, number of patients.

Pro275Ala, Gly369Ser and His441Arg) and one nonsense mutation at codon 293 (Arg293X), which serve an important role in the function and structure of MSR1, were identified (16). The SNP P275A is associated with COPD susceptibility in smokers, as indicated through the results of the spirometry tests. For the quantitative lung function measures analyzed using spirometry in the total population of smokers, subjects with the CG genotype at P275A exhibited a significantly lower $\mathrm{FEF}_{25-75}$ compared with the CC subjects $(\mathrm{P}=0.03)(10,20)$. However, these results are inconsistent with those of the present study. In the present study, 100 patients with COPD with lung cancer, 100 patients with COPD without lung cancer and 100 healthy controls were genotyped. The results revealed no significant association between the eight aforementioned variants and COPD risk, which were inconsistent with the studies performed by Ohar et al (10) and Ben et al (20). The heterogeneity observed in these previous studies may be due to the genetic background and sample size.

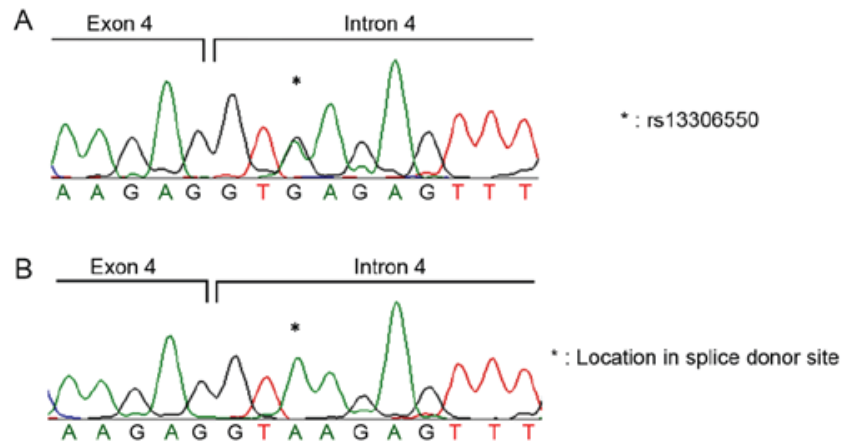

Figure 1. Identifying the splice donor site mutation rs13306550 (IVS4+3A) of the macrophage scavenger receptor 1 gene. (A) DNA sequence analysis of exon and intron 4. (B) Patient without the polymorphism. *The position of the mutation rs13306550 (IVS4+3A).

Although no significant association with regard to these eight variants was observed, the SNP rs13306550 was demonstrated 
Table V. Association of the single-nucleotide polymorphism rs 13306550 with COPD severity.

\begin{tabular}{lccr}
\hline & \multicolumn{3}{c}{ Genotype } \\
\cline { 2 - 4 } Severity & \multicolumn{1}{c}{ AA } & AG + GG & P-value \\
\hline $\mathrm{FEV}_{1} / \mathrm{FVC} \%$ & $48.55(57.90-39.93)$ & $43.30(64.00-41.30)$ & 0.9904 \\
$\mathrm{FEV}_{1} \%$ predicted & $35.97(48.86-28.08)$ & $32.81(40.58-28.93)$ & 0.6502 \\
$\mathrm{CAT}$ & $25.50(28.75-22.00)$ & $28.00(30.00-25.00)$ & 0.4036 \\
\hline
\end{tabular}

CAT, COPD Assessment Test; FVC, forced vital capacity; $\mathrm{FEV}_{1}$, forced expiratory volume in 1 sec; COPD, chronic obstructive pulmonary disease. Data regarding the lung function and the CAT score did not conform to the normal distribution; these were expressed as the median (Q3-Q1).

to be associated with COPD morbidity. Of the patients with COPD, $10 \%$ tested positive for the variant, while only one of the healthy controls was positive for it. Furthermore, $13 \%$ of the patients with COPD and lung cancer tested positive for the variant but no significant difference was identified between patients with COPD with and without lung cancer. That this polymorphism is associated with COPD susceptibility, but does not influence the pathogenesis of lung cancer in patients with COPD, could explain the results obtained.

Scavenger receptors on alveolar macrophages are crucial for identifying and eliminating airborne microorganisms and inhaled particles (21). Irritants, including cigarette smoke, may activate macrophages, resulting in inflammation through the release of neutrophil, monocyte, and T-lymphocyte chemotactic factors (22). Multiple mechanisms, including infection, apoptosis and oxidative stress characterize COPD pathogenesis (23). In innate immunity, alveolar macrophages represent the initial line of host immune defenses responsible for the reactions that cigarette smoke may activate. Alveolar macrophages are also associated with cytokine secretion $(24,25)$. These functional responses result in chronic inflammatory conditions and tissue destruction, which may enhance the emphysema commonly observed in patients with COPD (26-28). Kaku et al (29) revealed that MSR1 was overexpressed in patients with COPD and may be associated with COPD pathogenesis.

It was reported that MSR1 expression is decreased in tumor tissues compared with in normal tissues, and that this decreased MSR1 expression enhanced the growth and angiogenesis of lung carcinoma in mice (20). Therefore, the overexpression of MSR1 in patients with COPD may not induce lung cancer pathogenesis and the SNP rs13306550 may not influence lung cancer susceptibility in patients with COPD.

The present study confirmed the location of the SNP rs13306550 in MSR1. Rs13306550 (IVS4+3A) is located in the splice donor site of exon 4 of MSR1 (30). During evolution, splice donor sites and splice acceptor sites are commonly conserved. Mutations at the aforementioned splice site have been revealed to be associated with multiple genetic disorders (31). The creation of pseudo-exons within introns, intron retention, exon skipping and the activation of cryptic splice sites result from abnormal pre-mRNA splicing, which usually results from splice site mutations (32). In the present study, the distribution frequencies of the SNP rs13306550 differed significantly between the patients and the controls. Considering the location of this variant, it may be associated with COPD susceptibility.

As aforementioned, MSR1 is a macrophage scavenger receptor that identifies and clears potential pathogens during COPD exacerbation, including inhaled particles and microorganisms, modified lipids and apoptotic cells $(33,34)$. Therefore, MSR1 is associated with the pathogenesis and exacerbation of COPD. However, no significant association was identified between the SNP rs13306550 and the lung function test outcomes or the CAT scores. Therefore, this variant may influence only COPD pathogenesis and not its exacerbation. However, the small sample size renders conclusions regarding the function of the rs13306550 SNP challenging.

To conclude, the present study demonstrated that the SNP rs13306550 represented a risk factor for COPD susceptibility, but does not influence lung cancer pathogenesis in patients with COPD. However, the mechanisms underlying how this variant influences the development and progression of COPD remain to be fully understood and require further study.

\section{Acknowledgements}

The authors would like to thank Dr. Yuan from the Department of Pathology, Shanghai Ruijin Hospital Affiliated to the School of Medicine, Shanghai Jiao Tong University, Shanghai, China.

\section{Funding}

The present study was supported by the Chinese National Natural Science Foundation (grant no. 81570029) and Shanghai Key Discipline for Respiratory Diseases (grant. no., 2017ZZ02014).

\section{Availability of data and material}

The datasets used and analyzed during the current study are available from the corresponding author on reasonable request.

\section{Authors' contributions}

LX performed the experiments and wrote the whole manuscript. WC analyzed and interpreted the patient data with LX. $\mathrm{RD}$ and $\mathrm{BH}$ produced the blood samples of the subjects. $\mathrm{KZ}$ and LZ helped perform the experiments. MZ and PH contributed to the ideas of the research and provided financial support. 


\section{Ethics approval and consent to participate}

The protocol was reviewed and approved by the Ruijin Hospital Ethics Committee of Shanghai Jiao Tong University, School of Medicine (Shanghai, China).

\section{Consent for publication}

All patients who participated in the present study provided written informed consent for publication of the associated data and accompanying images.

\section{Competing interests}

The authors declare that they have no competing interests.

\section{References}

1. Ko FW, Chan KP, Hui DS, Goddard JR, Shaw JG, Reid DW and Yang IA: Acute exacerbation of COPD. Respirology 21: 1152-1165, 2016.

2. Gridelli C, Rossi A, Carbone DP, Guarize J, Karachaliou N, Mok T, Petrella F, Spaggiari L and Rosell R: Non-small-cell lung cancer. Nat Rev Dis Primers 1: 15009, 2015.

3. Houghton AM: Mechanistic links between COPD and lung cancer. Nat Rev Cancer 13: 233-245, 2013.

4. Putcha N, Barr RG, Han MK, Woodruff PG, Bleecker ER, Kanner RE, Martinez FJ, Smith BM, Tashkin DP, Bowler RP, et al: Understanding the impact of second-hand smoke exposure on clinical outcomes in participants with COPD in the SPIROMICS cohort. Thorax: thoraxjnl-2015-207487, 2016.

5. Dong R, Xie L, Zhao K, Zhang Q, Zhou M and He P: Cigarette smoke-induced lung inflammation in COPD mediated via LTB4/BLT1/SOCS1 pathway. Int J Chron Obstruct Pulmon Dis 11: 31-41, 2015.

6. Cheng L,Liu J,Li B,Liu S,LiX and Tu H: Cigarette smoke-induced hypermethylation of the GCLC gene is associated with COPD. Chest 149: 474-482, 2016.

7. Kim CH, Lee YC, Hung RJ, McNallan SR, Cote ML, Lim WY, Chang SC, Kim JH, Ugolini D, Chen Y, et al: Exposure to secondhand tobacco smoke and lung cancer by histological type: A pooled analysis of the international lung cancer consortium (ILCCO). Int J Cancer 135: 1918-1930, 2014.

8. Bossé Y: Updates on the COPD gene list. Int J Chron Obstruct Pulmon Dis 7: 607-631, 2012.

9. Hersh CP, DeMeo DL, Raby BA, Litonjua AA, Sylvia JS, Sparrow D, Reilly JJ and Silverman EK: Genetic linkage and association analysis of copd-related traits on chromosome $8 \mathrm{p}$. COPD 3: 189-194, 2006.

10. Ohar JA, Hamilton RF Jr, Zheng S, Sadeghnejad A, Sterling DA, Xu J, Meyers DA, Bleecker ER and Holian A: COPD is associated with a macrophage scavenger receptor-1 gene sequence variation. Chest 137: 1098-1107, 2010

11. Canton J, Neculai D and Grinstein S: Scavenger receptors in homeostasis and immunity. Nat Rev Immunol 13: 621-634, 2013.

12. Peiser L, Mukhopadhyay S and Gordon S: Scavenger receptors in innate immunity. Curr Opin Immunol 14: 123-128, 2002.

13. Taylor AE, Finney-Hayward TK, Quint JK, Thomas CM, Tudhope SJ, Wedzicha JA, Barnes PJ and Donnelly LE: Defective macrophage phagocytosis of bacteria in COPD. Eur Respir J 35: 1039-1047, 2010.

14. Hirayama S, Ishii G, Nagai K, Ono S, Kojima M, Yamauchi C, Aokage K, Hishida T, Yoshida J, Suzuki K and Ochiai A: Prognostic impact of CD204-positive macrophages in lung squamous cell carcinoma: Possible contribution of Cd204-positive macrophages to the tumor-promoting microenvironment. J Thorac Oncol 7: 1790-1797, 2012.

15. Emi M, Asaoka H, Matsumoto A, Itakura H, Kurihara Y, Wada Y, Kanamori H, Yazaki Y, Takahashi E, Lepert M, et al: Structure, organization, and chromosomal mapping of the human macrophage scavenger receptor gene. J Biol Chem 268: 2120-2125, 1993.
16. Walsh PC: Germline mutations and sequence variants of macrophage scavenger receptor 1 gene are associated with prostate cancer risk. J Urol 169: 1589-1590, 2003.

17. Pauwels RA, Buist AS, Calverley PM, Jenkins CR and Hurd SS; GOLD Scientific Committee: Global strategy for the diagnosis, management, and prevention of chronic obstructive pulmonary disease. NHLBI/WHO global initiative for chronic obstructive lung disease (GOLD) workshop summary. Am J Respir Crit Care Med 163: 1256-1276, 2001.

18. Rabe KF, Hurd S, Anzueto A, Barnes PJ, Buist SA, Calverley P, Fukuchi Y, Jenkins C, Rodriguez-Roisin R, van Weel C, et al: Global strategy for the diagnosis, management, and prevention of chronic obstructive pulmonary disease: GOLD executive summary. Am J Respir Crit Care Med 176: 532-555, 2007.

19. Grenier PA, Beigelman-Aubry C, Fetita CI and Brillet PY: CT imaging of chronic obstructive pulmonary disease: Role in phenotyping and interventions. Expert Opin Med Diagn 3: 689-703, 2009.

20. Ben J, Jin G, Zhang Y, Ma B, Bai H, Chen J, Zhang H, Gong Q, Zhou X, Zhang H, et al: Class A scavenger receptor deficiency exacerbates lung tumorigenesis by cultivating a procarcinogenic microenvironment in humans and mice. Am J Respir Crit Care Med 186: 763-772, 2012.

21. Palecanda A and Kobzik L: Receptors for unopsonized particles: The role of alveolar macrophage scavenger receptors. Curr Mol Med 1: 589-595, 2001.

22. Barnes PJ: Alveolar macrophages as orchestrators of COPD. COPD 1: 59-70, 2004

23. Valacchi G, Maioli E, Sticozzi C, Cervellati F, Pecorelli A, Cervellati $\mathrm{C}$ and Hayek J: Exploring the link between scavenger receptor B1 expression and chronic obstructive pulmonary disease pathogenesis. Ann N Y Acad Sci 1340: 47-54, 2015.

24. Barnes PJ: Inflammatory mechanisms in patients with chronic obstructive pulmonary disease. J Allergy Clin Immunol 138: 16-27, 2016.

25. Nurwidya F, Damayanti T and Yunus F: The role of innate and adaptive immune cells in the immunopathogenesis of chronic obstructive pulmonary disease. Tuberc Respir Dis (Seoul) 79: 5-13, 2016.

26. Liu G and Yang H: Modulation of macrophage activation and programming in immunity. J Cell Physiol 228: 502-512, 2013.

27. Cheng C, Huang C, Ma TT, Bian EB, He Y, Zhang L and Li J: SOCS1 hypermethylation mediated by DNMT1 is associated with lipopolysaccharide-induced inflammatory cytokines in macrophages. Toxicol Lett 225: 488-497, 2014.

28. Cosio MG, Saetta M and Agusti A: Immunologic aspects of chronic obstructive pulmonary disease. N Engl J Med 360: 2445-2454, 2009.

29. Kaku Y, Imaoka H, Morimatsu Y, Komohara Y, Ohnishi K, Oda H, Takenaka S, Matsuoka M, Kawayama T, Takeya M and Hoshino T: Overexpression of CD163, CD204 and CD206 on alveolar macrophages in the lungs of patients with severe chronic obstructive pulmonary disease. PLoS One 9: e87400, 2014.

30. Lindmark F, Jonsson BA, Bergh A, Stattin P, Zheng SL, Meyers DA, Xu J and Gronberg H: Analysis of the macrophage scavenger receptor 1 gene in Swedish hereditary and sporadic prostate cancer. Prostate 59: 132-140, 2004.

31. Zeng L, Liu W, Feng W, Wang X, Dang H, Gao L, Yao J and Zhang X: A novel donor splice-site mutation of major intrinsic protein gene associated with congenital cataract in a Chinese family. Mol Vis 19: 2244-2249, 2013.

32. Krawczak M, Reiss J and Cooper DN: The mutational spectrum of single base-pair substitutions in mRNA splice junctions of human genes: Causes and consequences. Hum Genet 90: 41-54, 1992.

33. Kuronuma K, Sano H, Kato K, Kudo K, Hyakushima N Yokota S, Takahashi H, Fujii N, Suzuki H, Kodama T, et al: Pulmonary surfactant protein A augments the phagocytosis of Streptococcus pneumoniae by alveolar macrophages through a casein kinase 2-dependent increase of cell surface localization of scavenger receptor A. J Biol Chem 279: 21421-21430, 2004.

34. Taylor PR, Martinez-Pomares L, Stacey M, Lin HH, Brown GD and Gordon S: Macrophage receptors and immune recognition. Annu Rev Immunol 23: 901-944, 2005. 